Full citation: McLeod, L., MacDonell, S.G., \& Doolin, B. (2007) Standard method use in contemporary IS development: an empirical investigation, Journal of Systems and Information Technology 9(1), pp.6-29.

http://dx.doi.org/10.1108/13287260710817665

\title{
Standard Method Use in Contemporary IS Development: An Empirical Investigation
}

\author{
Laurie McLeod, Stephen MacDonell \\ SERL \\ Auckland University of Technology \\ Private Bag 92006, Auckland 1142 \\ New Zealand \\ \{laumcl88,stephen.macdonell\}@aut.ac.nz
}

\author{
Bill Doolin \\ Faculty of Business \\ Auckland University of Technology \\ Private Bag 920006, Auckland 1142 \\ New Zealand \\ bdoolin@aut.ac.nz
}

\begin{abstract}
Purpose: The purpose of this study was to obtain an updated assessment of the use of standard methods in IS development practice in New Zealand, and to compare these practices to those reported elsewhere.

Design/methodology/approach: A Web-based survey of IS development practices in New Zealand organisations with 200 or more full-time employees was conducted. The results of the survey were compared to prior studies from other national contexts.

Findings: The results suggest that levels of standard method use continue to be high in New Zealand organisations, although methods are often used in a pragmatic or ad hoc way. Further, the type of method used maps to a shift from bespoke development to system acquisition or outsourcing. Organisations that reported using standard methods perceived them to be beneficial to IS development in their recent IS projects, and generally disagreed with most of the published limitations of standard methods.
\end{abstract}

Limitations: As the intent was to consider only New Zealand organisations, the results of the survey cannot be generalised further afield. More comparative research is needed to establish whether the trends identified here occur at a wider regional or international level.

Practical implications: A significant proportion of organisations anticipated extending their use of standard methods. Growth in packaged software acquisition and outsourced development suggests an increasing need for deployment management as well as development management, possibly reflecting the increased visibility of standard project management methods.

Originality/value: The relevance of traditional standard methods of IS development has been questioned in a changing and more dynamic IS development environment. This study provides as updated assessment of standard method use in New Zealand organisations that will be of interest to researchers and practitioners monitoring IS development and acquisition elsewhere.
Keywords: IS development, standard methods, empirical survey, New Zealand

\section{INTRODUCTION}

A standard method of information systems (IS) development is a formal or documented set of procedures for directing or guiding IS development, whether commercially or publicly available, or developed internally by an organisation. The focus of a standard method in IS is not just on software development, but on the analysis, design and implementation of the whole system (Wynekoop and Russo 1995). This use of 'method' to refer to the codified systematic conduct of IS development is primarily European. North American usage tends to refer to a method as a 'methodology' (Iivari et al. 2000/2001; Robey et al. 2001). Each standard method embodies a set of guiding principles and is based upon a particular philosophy, paradigm or approach to IS development. Usually, each method is supported by a set of preferred development techniques and tools (Fitzgerald et al. 2002; Iivari et al. 2000/2001; Iivari and Maansaari 1998; Robey et al. 2001; Wynekoop and Russo 1995, 1997).

According to much of the IS literature, use of an appropriate standard method of IS development can improve both the development process and its outcomes, particularly in large or complex IS projects (Butler and Fitzgerald 1999; Chatzoglou 1997; Fitzgerald 1998c; Kim and Peterson 2003; Wixom and Watson 2001). A standard method is considered to facilitate the development process by supplying an element of control (perceived or actual) over aspects such as the sequence of development activities, project management, cost allocation, project team composition and user participation (Lyytinen and Hirschheim 1987). Conversely, lack of or inappropriate use of a standard method is often considered to increase the risk of IS project failure (Ewusi-Mensah 1997; Lyytinen and Hirschheim 1987; Pan et al. 2004; Roberts 
et al. 1999; Schmidt et al. 2001; Wynekoop and Russo 1995).

A number of empirical studies, however, have failed to find a significant association between the use of standard methods and IS project success (Amoako-Gyampah and White 1993; Barry and Lang 2003; Fitzgerald 1998a; Jiang and Klein 1999, 2000; Martin and Chan 1996). Certainly, relative to other factors influencing IS development, use of a standard method has not usually been regarded as a primary mechanism for improving IS project outcomes, and may not be enough in itself to ensure success of an IS project (Barry and Lang 2003; Mathiassen and Purao 2002; Warne and Hart 1996). Kiely and Fitzgerald (2003) suggest, for instance, that standard methods can be of help if used properly by experienced developers, but are still unlikely to solve all IS development problems.

Since the late 1990s, various researchers and practitioners have, therefore, questioned the relevance of traditional standard methods and their underlying concepts, particularly in light of the more dynamic IS development environment characterised by short-term business needs, rapid application development, Internet and multimedia applications, and different IS acquisition options (Avison and Fitzgerald 2003; Fitzgerald 1996, 1998b, 2000; Fitzgerald et al. 2002; Fitzgerald et al. 1999; Iivari et al. 2000/2001; Kautz et al. 2004; Kiely and Fitzgerald 2003; Nandhakumar and Avison 1999; Sawyer 2001; Wynekoop and Russo 1997). It seems that some organisations are now trying new methods, or even rejecting the use of methods altogether. Other organisations are employing alternatives to traditional inhouse IS development, such as incremental development or continuous redevelopment of IS, contingent use of individual tools and techniques, packaged software acquisition or outsourced IS development (Avison and Fitzgerald 1999, 2003; Avison et al. 1992; Madsen and Kautz 2002; Truex et al. 1999).

Given the changing IS development environment, empirical knowledge of the current forms of IS development practice, such as standard method use, is needed (Barry and Lang 2003; Ljung and Allwood 1999). Surveys are a useful tool for gathering descriptive information from a large sample, providing a 'snapshot' of practices in use and opinions regarding their effectiveness (Fitzgerald et al. 1999; Wynekoop and Russo 1995, 1997). Here, we report the results of a survey conducted on standard method use in recent IS projects in New Zealand organisations. A principal objective of the study was to obtain an updated and detailed understanding of actual standard method use in New Zealand organisations and to compare that practice with standard method use in other national contexts.

The remainder of the paper is structured as follows. First, we review prior empirical studies of standard method use. We then outline the development of our survey instrument and the data collection procedure used in this study. Subsequent sections present and discuss the results of the survey, before some concluding remarks are made about the findings.

\section{PRIOR STUDIES OF STANDARD METHOD USE}

Empirical studies of standard method use since 1995 suggest that in general more organisations use a standard method than not, although reported use has no apparent pattern over time or by different national contexts (Table 1). In relation to New Zealand, a preliminary investigation of software development practices involving 26 organisations of variable size found that only $15 \%$ reported not using a standard method (Taylor 2000). Some $27 \%$ of the organisations used a formal standard method. These tended to be larger organisations, which is consistent with Urban and Whiddett (1996) who found that, in New Zealand, structured methods are more likely to be used by large organisations. The majority of organisations in Taylor's (2000) study (58\%) had an ad hoc approach to development, using an informal framework to guide development or adapting a standard method.

The use of standard methods by organisations needs some qualification. First, organisations who claim to use a standard method often use more than one method (Barry and Lang 2003; Eva and Guilford 1996; Iivari and Maansaari 1998; Rahim et al. 1998; Russo et al. 1996; Schambach and Walstrom 2002-2003). Second, even though an organisation claims to use standard methods, it cannot be assumed that a method will be used in all their IS projects (Wynekoop and Russo 1995). For example, in their study of 92 US organisations, Russo et al. (1996) found that, while $80 \%$ of organisations reported using a standard method, close to half of those organisations (46\%) reported that at least some of their IS development was performed without using a standard method.

There are range of reasons why a particular standard method might be used in a given IS project. Hornby et al. (1992) found that the methods used by developers are heavily influenced by choices made by their organisation (although the developers have more control over how they use the methods). The decision may be taken by one or more of the groups with an interest in the project (e.g. top management, the IS function, users, or an external development company or consulting firm) (Chatzoglou and Macaulay 1996; Madsen and Kautz 2002). Although selection and adoption of standard methods is often regarded as a technical concern for the IS function, Sauer and Lau (1997) argue that other groups, such as users, can legitimately try to influence such decisions. Use of a particular standard method may be historical practice within an organisation or a policy requirement (Chatzoglou 1997; Chatzoglou and Macaulay 1996). Within a given organisation, method selection and use may depend on the specific project and its context (Butler and Fitzgerald 1999; Chatzoglou 1997; Chatzoglou and Macaulay 1996; Fitzgerald et al. 2002; Kautz et al. 2004; Russo et al. 1996; Wynekoop and Russo 1995). Trying a new development method during an important project or choosing the wrong method is perceived to be an important risk threatening successful completion of IS projects (Pan et al. 2004; Schmidt et al. 2001). This may arise in part because developers feel more comfortable with using their existing method and may become demotivated if a new method is used (Linberg 1999). 
Table 1: Reported use of standard methods

\begin{tabular}{|c|c|c|c|c|c|}
\hline \multirow[b]{2}{*}{ Study } & \multirow{2}{*}{$\begin{array}{c}\% \\
\text { organisations } \\
\text { using a } \\
\text { method }\end{array}$} & \multirow{2}{*}{$\begin{array}{l}\text { \% method } \\
\text { users using } \\
\text { commercial } \\
\text { method }\end{array}$} & \multicolumn{2}{|c|}{$\begin{array}{c}\text { \% method users using in- } \\
\text { house method }\end{array}$} & \multirow{2}{*}{$\begin{array}{c}\% \text { method } \\
\text { users using } \\
\text { method as } \\
\text { specified }\end{array}$} \\
\hline & & & Total & $\begin{array}{c}\text { Based on a } \\
\text { commercial } \\
\text { method }\end{array}$ & \\
\hline UK (Fitzgerald et al. 1999) & 57 & 11 & 89 & 30 & \\
\hline UK (Eva and Guilford 1996) & 76 & & & & 17 \\
\hline UK (Hardy et al. 1995) & 82 & 54 & 46 & & 12 \\
\hline UK (Wastell and Sewards 1995) & 65 & 58 & 42 & & \\
\hline Ireland (Kiely and Fitzgerald 2002) & 62 & 32 & 66 & & 19 \\
\hline Ireland (Barry and Lang 2001; 2003) & 75 & 24 & 76 & & \\
\hline Ireland (Fitzgerald 1998a) & 40 & 35 & 64 & 29 & 42 \\
\hline US (Russo et al. 1996) & 80 & 21 & 79 & 37 & 6 \\
\hline Finland (Iivari and Maansaari 1998) & 73 & 47 & 47 & 44 & \\
\hline Brunei (Rahim et al. 1998) & 67 & & 58 & & \\
\hline New Zealand (Taylor 2000) & 85 & & & & \\
\hline
\end{tabular}

Standard methods may be commercially available, published in academic or practice literature, or developed within an organisation (Wynekoop and Russo 1995). Some in-house methods can be based on a commercial or published method. Prior studies suggest that a reasonable proportion of organisations are not using commercial methods, choosing instead to develop their standard methods in-house (Table 1). Wastell and Sewards (1995) found that organisations that used in-house methods reported higher levels of measurable benefits to the organisation than those who used either structured methods or ad hoc approaches. In-house methods are often perceived to be inexpensive, and, because they are based on prior experiences, to be more amenable to being changed, to promote a greater sense of ownership, to reflect the organisational structure and culture, and to suit the needs of developers and the organisation. By contrast, commercial methods are often perceived to be too expensive, too inflexible, failing to fit or reflect specific organisational contexts (Fitzgerald et al. 1999; Kiely and Fitzgerald 2002, 2003). It has also been argued that traditional commercial methods may be unsuitable for the development of modern applications such as multi-media and web-based applications (Avison and Fitzgerald 2003; Barry and Lang 2003; Kiely and Fitzgerald 2003; Taylor et al. 2002).

The level of detail provided by a standard method can vary from broad guidelines to detailed specifications of the steps to be carried out in a prescribed order. It has been argued that, because of the uniqueness of each IS project, detailed prescriptive methods are impractical and that instead methods should provide guidance to inform or support developers' judgement and decisions (Fitzgerald 2000; Fitzgerald et al. 2002; Vidgen et al. 2004). Standard methods comprising broad guidelines are often favoured by more experienced developers, while methods comprising detailed specifications can be perceived as being useful by inexperienced developers who then rely heavily on them and follow them strictly (Fitzgerald 1997, 1998b, 1998c; Fitzgerald et al. 2002).
Prior empirical studies addressing the adherence to standard methods in practice reveal that they are only being used as specified within the method in a limited number of organisations (Table 1). Instead, standard methods are often not rigorously followed or are adapted to fit the specific characteristics of an organisation or project (e.g. the complexity of the project, or the time, human resources or money available) on a systematic or ad hoc basis, or to suit client preferences (Barry and Lang 2003; Coughlan et al. 2003; Fitzgerald 2000; Groves et al. 2000; Hornby et al. 1992; Kiely and Fitzgerald 2003; Taylor 2000; Wynekoop and Russo 1997). Adaptation may include removal of parts of a method, addition of supplementary techniques, or a differing interpretation of a method (Bansler and Bødker 1993; Butler and Fitzgerald 1999; Fitzgerald 1996, 1997; Fitzgerald et al. 2002; Hardy et al. 1995; Iivari et al. 2000/2001; Kautz et al. 2004; Kiely and Fitzgerald 2003; Nandhakumar and Avison 1999; Westrup 1993; Wynekoop and Russo 1995, 1997). Some empirical studies have shown that strict adherence to a method does not match how developers work in practice and may even be counter-productive (Kautz and McMaster 1994; Wastell 1996). Indeed, some standard methods may be too structured to be practical on a daily basis (Nandhakumar and Avison 1999).

Varying levels of adherence notwithstanding, a number of empirical surveys and case studies have highlighted that standard methods are largely perceived to be beneficial, particularly (and not unexpectedly) by people who use them (e.g. Chatzoglou 1997; Fitzgerald 1997; Iivari and Maansaari 1998; Kiely and Fitzgerald 2003; Nandhakumar and Avison 1999; Roberts et al. 2000; Schambach and Walstrom 2002-2003; Westrup 1993). Hardy et al. (1995) surveyed IS professionals in UKbased companies and found that, relative to other positive statements about standard methods, they agreed most that standard methods lead to specifications that match requirements and thus systems that meet users' requirements and with fewer errors in design. Respondents also felt, however, that standard methods were often complicated and time-consuming to use and 
provided poor coverage of the IS development lifecycle. Similar findings were obtained by Rahim et al. (1998), who surveyed IS managers in public and private sector organisations in Brunei Darussalam. The most widely perceived benefits were improved productivity, better communication with users, increased user participation and fulfilled user requirements. Problems perceived with standard method use included the time taken to learn them, increased project duration and incomplete coverage of the IS development lifecycle. Johnson and Hardgrave (1999) surveyed developers from various countries (mainly the US) about current practices with objectoriented methods. They found that the developers agreed most strongly that the methods made the system more understandable, were useful and increased their productivity, and were easy to learn and use. There was also agreement that the methods were effective in capturing requirements, led to improved user-developer communication and helped reduce the development time.

In a survey of Irish organisations, Fitzgerald (1998a) found that IS managers believed that standard methods facilitated project control and visibility of the IS development process. However, they also felt that methods were cumbersome, led to inertia in the development process, and could interfere with actual development work. In a later survey of Irish project managers, Kiely and Fitzgerald (2002) found that just under half (46\%) felt that their IS project could not have been completed without using a method, compared to $38 \%$ who felt that felt that their IS project could have been completed without using a method. The majority (90\%) of respondents who used a standard method felt that its use provided significant benefits to the IS development process, including as a project management and quality control aide. In terms of perceived disadvantages, many respondents felt that methods prolonged the development process. In their subsequently reported survey of traditional IS development in Irish companies, Barry and Lang (2003) found that the most common reasons for developers not using standard methods were that they were too cumbersome, too costly, were difficult to understand and use, required extensive training, and were not suited to the 'real world' of IS development.

To summarise the state of understanding prior to our own empirical research effort, it seems reasonable to suggest that standard methods have been widely used and are generally perceived of as delivering beneficial outcomes. That said, they are not without their perceived disadvantages, and there is a growing perception that the relevance of established methods has decreased in light of changes in the IS development environment.

\section{RESEARCH APPROACH}

In order to gain a broad understanding of New Zealand practitioner opinions and practices in relation to the use of standard methods we chose to conduct a survey. The survey instrument used was a multi-page Web-based design, created according to Dillman's (2000) principles for Web surveys (thus minimising the effects of measurement, non-response, coverage and sampling errors). The survey used a questionnaire to solicit information about aspects of IS development practice in New Zealand organisations, including standard method use in the IS development process.

The first few questions were general in nature, requiring intended respondents to state (or estimate where necessary) the total number of IS projects that had been undertaken and completed by their organisation during the three-year period 2001-2003. Those answering were also asked to classify these IS projects in terms of their cost (as a proxy for size), their IS development or acquisition type, and the levels of standard method use in the development process. For those projects where no standard method was used, respondents were asked to identify why that was the case.

Those respondents who had used a standard method in any of their IS projects were then asked to answer a series of questions related to the nature of that use. These questions addressed the reason for selecting the standard method(s) used, the origin of the standard method(s) used, the names of any commercial or published standard methods that were used, the level of detail in the standard method(s), and how frequently the standard method was used as specified. Respondents were then asked to indicate their level of agreement with various positive and negative statements about the use of standard methods that reflected the benefits and limitations of standard method use identified in the prior studies reviewed in the previous section. These statements are summarised in Table 2. In answering these questions, respondents were free to choose from a five-point Likert-type scale comprising "Strongly disagree”, ”Disagree”, ”Neutral”, "Agree” and "Strongly Agree” options, or alternatively a "Don’t know or Not applicable” option.

All respondents (whether standard method users or not) were asked to identify any changes in standard method use that they expected to see in their organisation in the subsequent three years. Finally, all respondents were asked to indicate their official position and to characterise their organisation in terms of business sector, organisational size, and the size and location of its IS function.

In order to verify the robustness of the survey instrument, it was pilot tested to 20 organisations in March 2004. We were reassured by the outcomes of this testing, making only a few minor modifications to question wording. The main survey was undertaken during April and May 2004. The target population was those organisations large enough to require IS beyond that which could be achieved by standard desktop applications, to have an inherent need for systematisation and computerised integration of business functions, and be more likely to utilise up-todate software innovations and development practices. Altogether, the survey was administered to $460 \mathrm{New}$ Zealand public and private sector organisations with 200 or more FTEs. The manager responsible for IS project work within the organisation (typically an IS/IT Manager or CIO) was targeted as the person most likely to have a knowledge of the organisation's IS development practice. In order to ensure currency of the results and to ensure more accurate recall by survey participants, the survey focused on IS projects undertaken and completed (or 
substantially completed) in the three calendar years 2001 to 2003.

The number of responses received was 113, for a response rate of 25\%. Seven responses were unusable, either because critical (demographic) data was missing or the reported organisational size was below 200 FTEs. This left 106 usable responses that formed the basis of subsequent data analysis (although not all respondents answered every question). Characteristics of the responding organisations are shown in Table 3. The 106 organisations in the respondent population represent $17 \%$ of the target population and provide a reasonable match with respect to business sector and organisational size. Just over half the organisations reported sizes of IS function of fewer than 10 FTEs, and in the majority of organisations (78\%) the IS function was located in one central unit.

Table 2: Items reflecting benefits and limitations of standard methods

\begin{tabular}{|c|c|}
\hline Positive statements about standard methods & Source \\
\hline Allowed movement of developers between projects & (Fitzgerald 1998a; Westrup 1993) \\
\hline Enabled us to manage costs effectively & $\begin{array}{l}\text { (Barry and Lang 2001, 2003; Chatzoglou 1997; } \\
\text { Fitzgerald 1998a; Hardy et al. 1995) }\end{array}$ \\
\hline Ensured the developed system met user requirements & $\begin{array}{l}\text { (Fitzgerald 1998a; Hardy et al. 1995; Roberts et al. } \\
\text { 2000) }\end{array}$ \\
\hline Ensured timely development of the system & $\begin{array}{l}\text { (Barry and Lang 2001; Chatzoglou 1997; Fitzgerald } \\
\text { 1998a; Hardy et al. 1995; Johnson and Hardgrave } \\
\text { 1999; Rahim et al. 1998) }\end{array}$ \\
\hline Ensured well-defined user requirements & $\begin{array}{l}\text { (Hardy et al. 1995; Johnson and Hardgrave 1999; } \\
\text { Rahim et al. 1998) }\end{array}$ \\
\hline Facilitated effective communication among developers & (Fitzgerald 1998a; Rahim et al. 1998) \\
\hline $\begin{array}{l}\text { Facilitated effective communication between developers } \\
\text { and users }\end{array}$ & $\begin{array}{l}\text { (Johnson and Hardgrave 1999; Rahim et al. 1998; } \\
\text { Roberts et al. 2000) }\end{array}$ \\
\hline Facilitated effective project control & $\begin{array}{l}\text { (Fitzgerald 1998a; Kiely and Fitzgerald 2002; Rahim } \\
\text { et al. 1998; Roberts et al. 2000) }\end{array}$ \\
\hline Facilitated successful IS development & $\begin{array}{l}\text { (Barry and Lang 2003; Fitzgerald 1998a; Westrup } \\
\text { 1993) }\end{array}$ \\
\hline Facilitated user participation in the development process & $\begin{array}{l}\text { (Hardy et al. 1995; Rahim et al. 1998; Westrup } \\
\text { 1993) }\end{array}$ \\
\hline Led to a high level of productivity of the project team & $\begin{array}{l}\text { (Fitzgerald 1997, 1998a; Hardy et al. 1995; Johnson } \\
\text { and Hardgrave 1999; Rahim et al. 1998; Roberts et } \\
\text { al. 2000) }\end{array}$ \\
\hline Led to the delivery of a high-quality system & $\begin{array}{l}\text { (Barry and Lang 2001; Fitzgerald 1998a; Hardy et } \\
\text { al. 1995; Rahim et al. 1998; Roberts et al. 2000) }\end{array}$ \\
\hline \multicolumn{2}{|l|}{ Negative statements about standard methods } \\
\hline Constrained developer creativity and flexibility & (Fitzgerald 1998a; Roberts et al. 2000) \\
\hline $\begin{array}{l}\text { Constrained effective user participation in the } \\
\text { development process }\end{array}$ & (Wastell 1996; Westrup 1993) \\
\hline Did not cover the entire development process & (Hardy et al. 1995; Rahim et al. 1998) \\
\hline Did not match how systems are actually developed & $\begin{array}{l}\text { (Barry and Lang 2003; Fitzgerald 1998a; Roberts et } \\
\text { al. 2000) }\end{array}$ \\
\hline Ignored developers' knowledge and experience & (Fitzgerald 1998a) \\
\hline Ignored people-related factors in development & (Fitzgerald 1998a) \\
\hline Was difficult to adapt to a specific situation & (Fitzgerald 1998a; Hidding 1997) \\
\hline Was difficult or time-consuming to learn or use & $\begin{array}{l}\text { (Barry and Lang 2001, 2003; Fitzgerald 1997, } \\
\text { 1998a; Hardy et al. 1995; Hidding 1997; Kiely and } \\
\text { Fitzgerald 2002; Rahim et al. 1998; Roberts et al. } \\
\text { 2000) }\end{array}$ \\
\hline
\end{tabular}


Table 3: Characteristics of respondent organisations

\begin{tabular}{|c|c|c|c|}
\hline Business Category & $\begin{array}{l}\text { \% organisations } \\
(\mathrm{n}=106)\end{array}$ & Size of IS function (FTE) & $\begin{array}{l}\text { \% organisations } \\
(\mathrm{n}=104)\end{array}$ \\
\hline Communications \& Media & 2 & Fewer than 4 & 23 \\
\hline Construction \& Engineering & 8 & 4 to 9 & 30 \\
\hline Education, Health \& Community Services & 16 & 10 to 19 & 9 \\
\hline Electricity, Gas \& Water Utilities & 3 & 20 to 49 & 13 \\
\hline Finance, Insurance \& Banking & 8 & 50 to 99 & 16 \\
\hline Government \& Local Government & 12 & 100 or more & 10 \\
\hline IT, Business, Legal \& Property Services & 8 & & \\
\hline Manufacturing \& Processing & 24 & Location of IS function & $\begin{array}{c}\text { \% organisations } \\
(\mathrm{n}=106)\end{array}$ \\
\hline Primary Industries & 1 & Centralised & 78 \\
\hline Tourism, Accommodation \& Food Services & 3 & Distributed & 12 \\
\hline \multirow[t]{2}{*}{$\begin{array}{l}\text { Transportation, Logistics } \quad \& \quad \text { Storage } \\
\text { Wholesale \& Retail Trade }\end{array}$} & 11 & Mainly outsourced & 8 \\
\hline & & Don’t know & 1 \\
\hline \multirow[t]{7}{*}{ Organisational size (FTE) } & $\begin{array}{l}\text { \% organisations } \\
\quad(\mathrm{n}=106)\end{array}$ & Respondent's role & $\begin{array}{l}\text { \% organisations } \\
(\mathrm{n}=106)\end{array}$ \\
\hline & 25 & Chief Information Officer & 22 \\
\hline & 13 & IS Manager & 45 \\
\hline & 19 & Development Manager & 9 \\
\hline & & Project Manager & 8 \\
\hline & & System Administrator & 5 \\
\hline & & Non-IS Manager & 10 \\
\hline
\end{tabular}

\section{RESULTS AND ANALYSIS}

\subsection{IS Projects}

Summary information relating to the IS projects reported on in the survey are presented in Table 4. The number of projects completed (or substantially completed) over the three year period surveyed varied significantly, ranging from 0 to 230 projects per organisation, with an average of 7 projects per organisation per year. Five percent of organisations did not undertake any IS projects during the period in question, while $59 \%$ of organisations undertook between 1 and 10 IS projects. The purchase of packaged software or applications made up just under half of the projects (46\%), with the remainder being bespoke developments. Further detailed analysis of these responses and others associated with general IS development practices can be found in McLeod et al. (2006).

\subsection{Extent of Standard Method Use}

Table 5 shows the extent of reported standard method use in the IS development process for the projects surveyed. Standard method use in at least part of the development process dominated, being cited in 91\% of the reported projects. Consideration of standard method use by organisation rather than project produced a very similar result, with $92 \%$ of organisations reporting use of a standard method in at least part of the development process in at least some of their IS projects. Compared to their smaller counterparts, larger organisations reported significantly more projects in which a standard method was used for more or less all $(U=884.5, \mathrm{p}=0.026)$, for only part $(U=959.5, \mathrm{p}=0.051)$, and for at least part $(U=810.5, \mathrm{p}=0.006)$ of the development process. Smaller organisations tended to report a higher median number of projects where a standard method was not used. Although the difference in median compared to the larger organisations was not significant $(U=1049.5, \mathrm{p}=0.171)$, this finding is consistent with prior studies that have shown that method use is correlated with organisation size (Fitzgerald 1998a; Kiely and Fitzgerald 2002; Russo et al. 1996; Urban and Whiddett 1996; Wastell and Sewards 1995).

Compared to prior empirical studies, and perhaps contrary to expectations (given that it was conducted more recently), this study shows higher reported levels of standard method use. For example, the proportion of reported projects in which a standard method was not 
used (9\%) is low compared with the 31\% reported for studies conducted in both the US (Russo et al. 1996) and the UK (Chatzoglou 1997). The proportion of organisations that reported using a standard method in this study (92\%) is higher than that previously reported, with these values ranging from $40 \%$ to $85 \%$, with an average of $69 \%$ (see Table 1). It is worth noting, however, that the highest prior reported level of method use (85\%) was from another New Zealand (albeit a small sample, preliminary) study (Taylor 2000). The proportion of organisations doing at least some of their IS development without using a standard method in this study (25\%) is again lower than the $46 \%$ reported by Russo et al. (1996). It does, however, still accord with Wynekoop and Russo (1995), who note that just because an organisation cites use of a standard method, it may not actually be used in all of there IS projects.

Table 4: IS project details

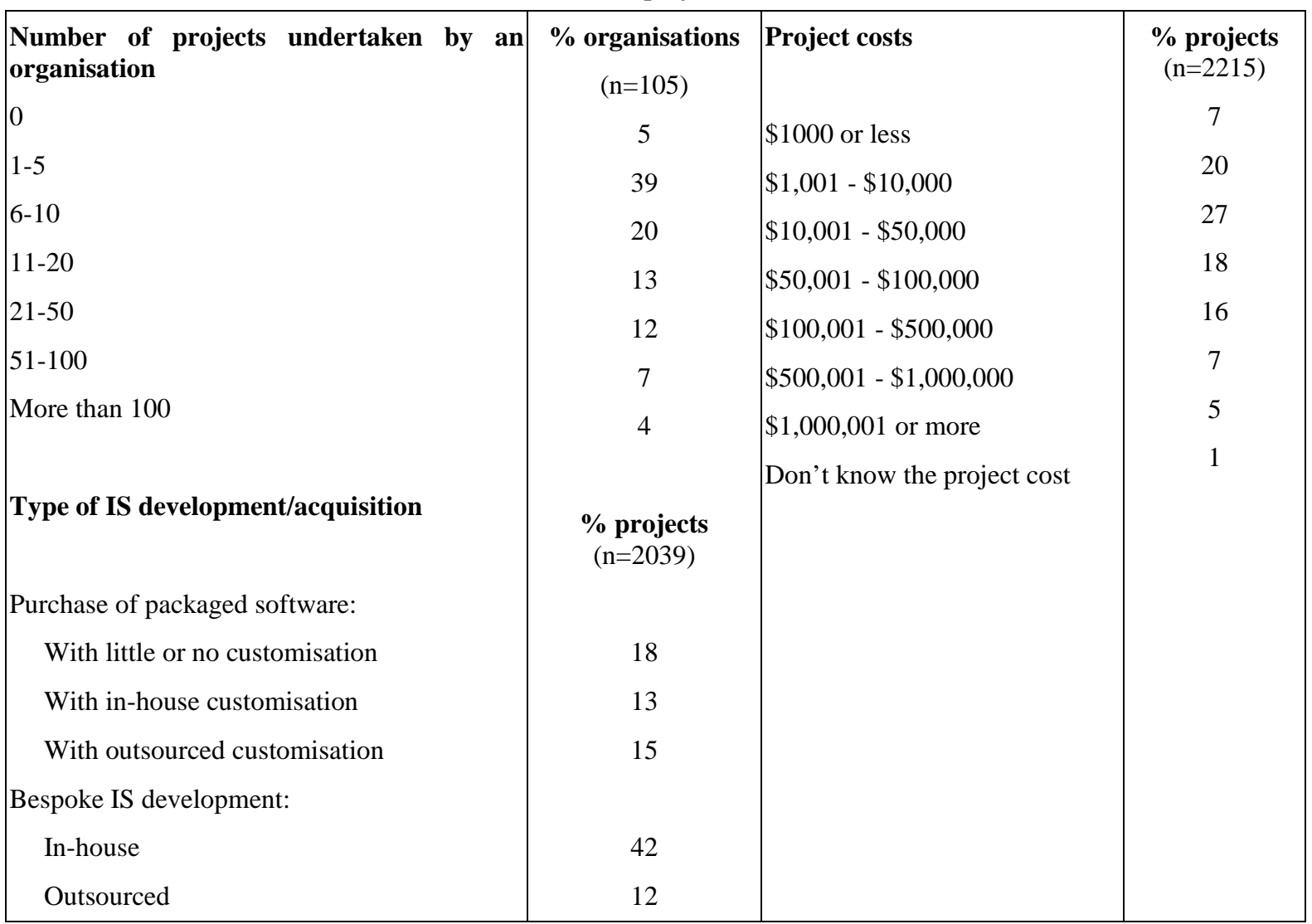

Table 5: Extent of standard method use

\begin{tabular}{|l|c|}
\hline & \% projects \\
(n=2026) \\
Standard method not used & 9 \\
Standard method used for more or less all of development & 77 \\
Standard method used for only part of development & 13 \\
& \% organisations \\
(n=99) \\
Standard method never used & 8 \\
Standard method used & 92 \\
Standard method used for more or less all of development in at least some projects & 85 \\
Standard method used for only part of development in at least some projects & 36 \\
Standard method not used in at least some projects & 25 \\
\hline
\end{tabular}


The most common reasons given for not using a standard method in particular IS projects were related to the nature of the project (e.g. the project was small or non-critical, was a packaged solution involving little or no customisation, or control of the project was outside the IS function) or to organisational practice (e.g. the organisation had an informal or ad hoc approach towards development or no method was in place in the organisation). These reasons are consistent with those identified in prior studies (Fitzgerald 1998a; Fitzgerald et al. 2002; Huisman and Iivari 2002; Kiely and Fitzgerald 2002, 2003; Roberts et al. 2000; Wynekoop and Russo 1995), and may indicate that organisations may choose to not use a standard method in a given IS project for pragmatic reasons (cf. Fitzgerald 1996; 1998a; 2000) rather than because there are fundamental problems with the methods themselves.

\subsection{Nature of Standard Method Use}

Of the 101 respondents to the survey who had conducted IS projects in the three-year timeframe, 92 had used a standard method to some extent. These respondents were asked to provide additional information on the nature of standard method use in their actual IS projects. Eighty of these respondents provided usable responses to this part of the questionnaire. Their responses (Table 6) form the basis of the following analysis.

Only $16 \%$ of the respondents chose their method(s) because of the fit of the method with the characteristics of the project, supporting Chatzoglou (1997, p. 256), who suggested that "developers are using methods for all sorts of reasons ... other than the right one (that is, suitability for the type of project they are currently working on)”. Just over half of the respondents (51\%) chose their standard method(s) for organisational reasons (because of organisational policy, historical practice within the organisation, or the choice of an external development organisation). A further $15 \%$ chose their method(s) for reasons related to the characteristics of the method (ease of use or quality of support) and $14 \%$ because of developer familiarity with the method. Close to a decade on, this echoes Chatzoglou and Macaulay's (1996, p. 218) observation that, "in many cases, a methodology is chosen not because of its characteristics or advantages over other methodologies, but simply for reasons of history and familiarity”.

The most common origin of the standard method(s) used in the IS projects undertaken by the responding organisations was the organisations themselves - most methods were developed in-house (81\%). The majority of these $(60 \%)$ were based on a commercial or published method. Although only $18 \%$ used a commercial standard method as published, overall in $67 \%$ of the responding organisations a commercial or published method was used in some form. These findings are consistent with earlier empirical studies, which show that a high proportion of organisations tend to develop their standard methods inhouse (42\% to $89 \%$, with an average of $63 \%$; see Table 1 ), rather than using commercial methods as published. Commercial methods (in some form) are being used by the organisations in this study (67\%) in proportions comparable to some prior studies (Fitzgerald 1998a; Russo et al. 1996) but not others (Iivari and Maansaari 1998). In contrast to other empirical studies (Fitzgerald 1998a; Fitzgerald et al. 1999; Russo et al. 1996), this study found that in-house methods were more commonly based on a commercial method than not, although not to the same level as Iivari and Maansaari (1998).

The preference for in-house methods may arise because they are often perceived to be cheaper, more flexible, and more relevant or suited to a given organisational context than commercial methods (Fitzgerald et al. 1999; Kiely and Fitzgerald 2002, 2003). Even so, commercial methods formed the basis of the majority of in-house developed methods used by organisations in this study, suggesting that these organisations perceive some value in using elements of commercial methods rather than developing their methods from first principles.

The prevalence of methods that include broad guidelines for development (79\% of respondents) fits with the argument that methods should provide guidance to inform and support developers (Fitzgerald 2000; Fitzgerald et al. 2002; Vidgen et al. 2004). Even so, the proportion of organisations who reported having methods with detailed specifications (62\%) suggests that some people believe that the detail may be of value. As stated previously, detailed prescriptions may be thought of as being invaluable to less experienced developers (Fitzgerald 1997, 1998b, 1998c; Fitzgerald et al. 2002). However, Hidding (1997) points out that it may not be so much the level of detail that is important as the type of information that is available. Further, just because the detail is there, does not mean to say that it is being used, or used effectively, as methods are often adapted to suit the project or are not used rigorously (Eva and Guilford 1996; Fitzgerald 1998a; Hardy et al. 1995; Kiely and Fitzgerald 2002; Russo et al. 1996).

Only $18 \%$ of respondents claimed to always use their method(s) as specified. This figure is comparable with the majority of values reported in the literature, which range from $6 \%$ to $42 \%$ with an average of $19 \%$ (see Table 1 ). This suggests that a large proportion of organisations at least sometimes adapt their methods to specific projects or do not use them to the letter. For example, one respondent commented that sometimes the standard method was "used more at the beginning, and then as we got closer to the deadline we tended to do things quicker and less rigidly”. Taylor (2000) suggests that New Zealand organisations tend to follow an ad hoc, pragmatic approach to development.

Thirty-five respondents supplied the names of commercial or published standard methods that had been used in the IS projects in their organisation over the threeyear timeframe (Table 7). Eleven of these reported using between two to five commercial or published standard methods. These respondents all previously reported typically using an in-house method based on a commercial or published one. In contrast, all nine respondents who previously reported typically using a commercial method provided the name of only one method. The implication is that the organisations using a commercial method seem to use it exclusively, while half of those organisations developing their own method based 
on a commercial one either derive their method from a variety of commercial methods or possibly use commercial methods only in certain circumstances.

The reported standard methods generally fell into three main groups. The largest group comprised methods derived from a vendor or other organisation (including government organisations). These are fairly well spread across a range of sources, including software vendors, enterprise systems vendors, consulting organisations, government agencies, and standards bodies. Another group of standard methods comprised those built around particular approaches to the IS development process. Again, these are fairly well spread across a range of approaches, but dominated by Rational Unified Process and the Waterfall method.

Table 6: Nature of standard method use

\begin{tabular}{|c|c|}
\hline Most common reason for method selection & $\begin{array}{c}\% \text { organisations } \\
\qquad(\mathrm{n}=79)\end{array}$ \\
\hline Organisational policy & 27 \\
\hline Historical practice in the organisation & 18 \\
\hline Fit with project characteristics & 16 \\
\hline Developer familiarity with method & 14 \\
\hline Ease of use of method & 11 \\
\hline Choice of external development company & 6 \\
\hline Quality of support for method & 4 \\
\hline Other & 4 \\
\hline Most common method origin & $\begin{array}{c}\text { \% organisations } \\
(\mathrm{n}=71)\end{array}$ \\
\hline Developed in-house & 32 \\
\hline Developed in-house based on commercial or published method & 49 \\
\hline Commercial or published method & 18 \\
\hline Level of detail provided by method & $\begin{array}{c}\text { \% organisations } \\
(\mathrm{n}=73)\end{array}$ \\
\hline Only broad guidelines & 38 \\
\hline Only detailed specifications & 21 \\
\hline Both broad guidelines and detailed specifications & 41 \\
\hline Extent of method use & $\begin{array}{c}\text { \% organisations } \\
(\mathrm{n}=67)\end{array}$ \\
\hline Always used as specified & 18 \\
\hline Often used as specified & 63 \\
\hline Sometimes used as specified & 19 \\
\hline Never used as specified & 0 \\
\hline
\end{tabular}


Table 7: Commercial or published standard methods used

\begin{tabular}{|l|}
\hline Methods related to development approaches \\
Rational Unified Process \\
Waterfall \\
Agile Development \\
RAD \\
SSADM \\
Total \\
Project management methods \\
PMI/ PMBOK \\
BearingPoints \\
Prince \\
Other \\
Total
\end{tabular}

The third group of methods reported comprised project management methods. Seven respondents reported using both standard methods and project management methods in their IS projects. The inclusion of project management methods among the list of reported standard methods may reflect changing IS development practices, such as higher levels of package acquisition or outsourced development, where the emphasis shifts from traditional standard development methods to project management. Certainly, the value of using a formal project management method and related project management practices is recognised in both the IS literature and IS practice (e.g. Gowan and Mathieu 2005; Johnson et al. 2001; Keil et al. 2002; Schmidt et al. 2001; Standish Group International 1999). As one survey respondent commented, "Project management and getting the right people (particularly from within the business) to project manage any IS project is key".

\subsection{Benefits of Standard Method Use}

Respondents were asked to indicate their level of agreement with various positive statements about the use of standard methods in their IS projects undertaken over the three-year time frame. These statements are shown in Figure 1, in order of level of agreement. The mean ratings for all statements are above the neutral value of 3 , implying that these respondents (who had used a standard method to at least some extent) tended to agree with these benefits of standard methods (recall that the 5-point Likert scale labels were assigned a value from 1 (strong disagreement) to 5 (strong agreement)). Further, there were very low levels of disagreement reported, with no more than two respondents disagreeing with the top seven statements. The mean ratings and level of agreement obtained in this study compare closely with those obtained by Rahim et al. (1998) (where the mean rating varied from 4.30 to 3.57) and Hardy et al. (1995) (where the \% agreement ranged from 96 to $60 \%$ ), respectively. It seems that organisations that use standard methods for IS development are confident of the benefits of doing so.

Almost all respondents (90\%) agreed that standard method use facilitated successful IS development. Two other statements focusing on definitional aspects of IS success, standard methods ensured the developed IS met user requirements and led to delivery of a high quality system, also ranked highly. Interesting, not one respondent disagreed with the latter statement. The

\begin{tabular}{|c|l|c|}
\hline $\mathbf{n}$ & Methods derived from organisations & $\mathbf{n}$ \\
6 & External consultants & 6 \\
5 & Enterprise systems (e.g. SAP) & 4 \\
3 & Oracle & 4 \\
3 & IBM & 3 \\
2 & Government agencies & 3 \\
19 & ISO & 2 \\
& Other & 1 \\
& Total & 23 \\
7 & & 3 \\
2 & Other standard methods & \\
2 & & \\
2 & & \\
13 & & \\
\hline
\end{tabular}

respondents also tended to agree that use of a standard method assisted in aspects of the IS development process, particularly in relation to requirements definition, project control, and communication between developers and users. Overall, respondents were less convinced that using a standard method allowed movement of developers between IS projects or increased productivity of the project team. The latter result could reflect the stronger influence of factors other than standard method use on project team performance (Guinan et al. 1998).

A comparison of the empirical literature (Table 8) shows that the importance of standard methods to ensuring that the developed IS meets user requirements identified here is supported by other studies (Hardy et al. 1995; Rahim et al. 1998). Also, as in this study, Fitzgerald (1998a) found that Irish IS managers perceived the project management role of standard methods as being of high importance. The same result was reported in a later study by Kiely and Fitzgerald (2002). In contrast, Rahim et al. (1998) found that project control was perceived to be the least important benefit in their survey. The highest ranked benefits in the Rahim et al. (1998) study, the role of standard methods in improving productivity (see also Johnson and Hardgrave 1999), facilitating communication with users, and enabling user participation, were ranked as less important in the current study.

Respondents agreed most (25\%) with the statement that suggested that the standard methods that they used in their projects did not cover the entire development process. Overall, respondents seemed ambivalent about this statement, with 36\% neutral and only 39\% disagreeing. Fewer respondents (19\%) agreed that standard methods ignored people-related factors. There was some agreement that standard methods were difficult or timeconsuming to learn or use, constrained developers' creativity and flexibility, and were difficult to adapt to a specific situation. Respondents disagreed most with the statements that suggested standard methods inhibited developers from using their knowledge or experience and constrained effective user participation.

A comparison of these results to the reported empirical literature (Table 9) shows that the highest ranked limitation of standard method use in this study, that the standard methods did not cover the entire development process, is consistent with Hardy et al. (1995) and Rahim et al. (1998), who also reported relatively high rankings for similar statements. The relatively high ranking reported in this study for standard methods being difficult 
or time-consuming to learn or use is consistent with other empirical studies that highlight the perceived negative effect of standard method use on project development times (Fitzgerald 1998a; Hardy et al. 1995; Kiely and Fitzgerald 2002; Rahim et al. 1998), or that standard methods can be cumbersome (Barry and Lang 2003; Fitzgerald 1998a) or require extensive training to use (Rahim et al. 1998). The low ranking given in this study to the perceived limitation that the standard method did not match how systems are actually developed is consistent with Barry and Lang (2003), but contrasts with the findings of Fitzgerald (1998a).

\subsection{Limitations of Standard Method Use}

Respondents were asked to indicate their level of agreement with various negative statements about the use of standard methods in their IS projects undertaken over the three-year time frame. These statements are shown in Figure 2, in order of level of agreement. The mean ratings for all statements are below the neutral value of 3 , implying that respondents tended to disagree with these negative statements about the use of standard methods in the projects reported on in this survey. This is consistent with the overall beneficial perception of the use of standard methods identified above. However, it should be noted that compared to the rating of positive statements, respondents' ratings of the negative statements were more widely spread across the range of possible responses. What these results suggest is that, although these published limitations may occur on a case by case basis, they are not of sufficient magnitude to adversely influence the respondents' overall perceptions of standard method use in their IS projects.

Figure 1: Relative agreement with positive statements about standard methods

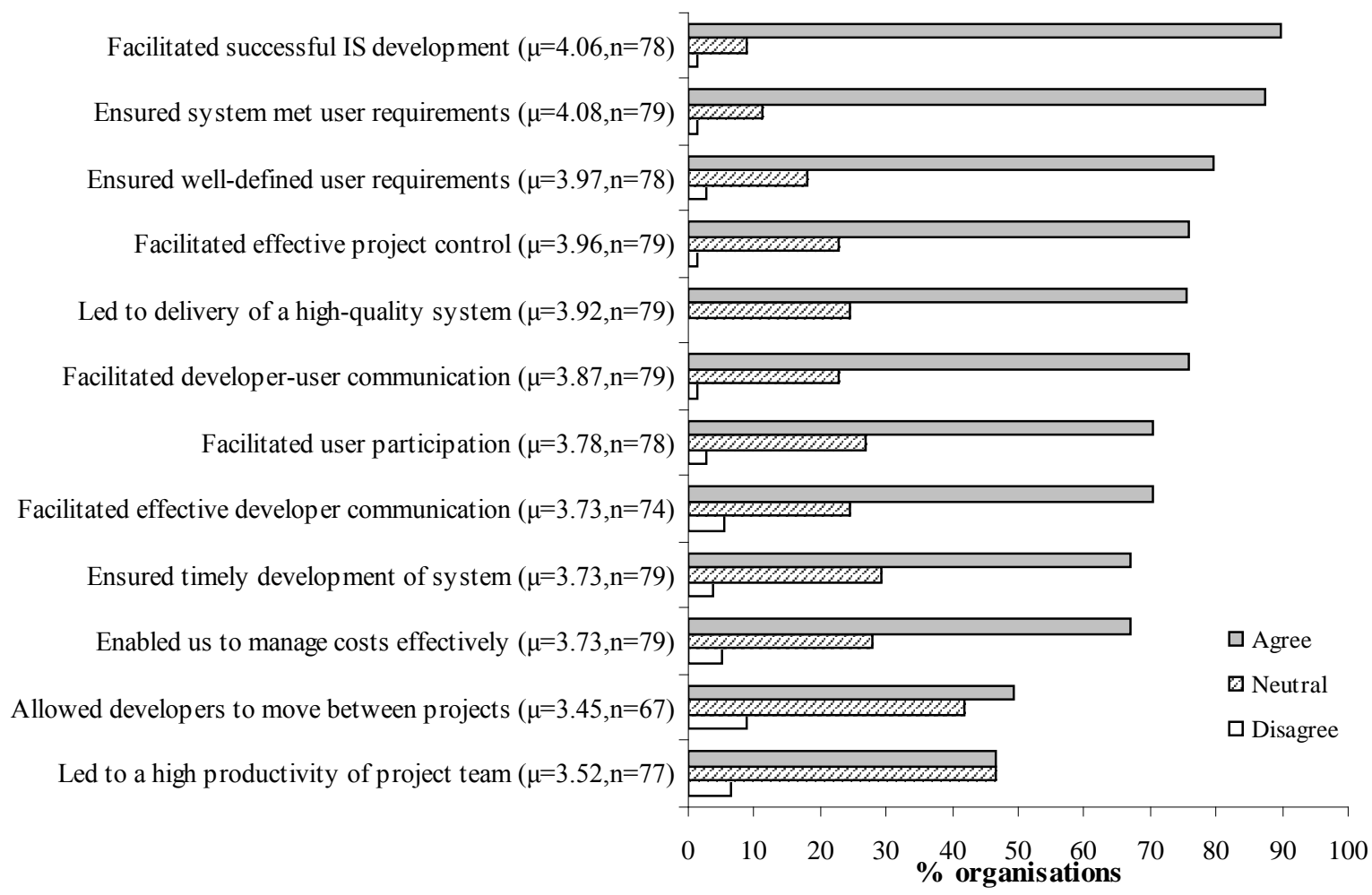

Table 8: Comparative ranking of benefits of standard methods

\begin{tabular}{|c|c|c|c|c|c|}
\hline Role of standard method use & 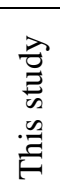 & 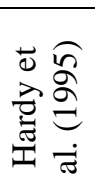 & 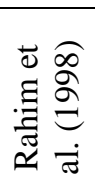 & 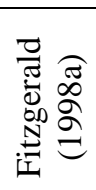 & 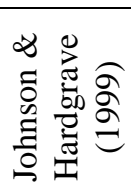 \\
\hline Total number of factors ranked & 12 & 8 & 9 & 10 & 9 \\
\hline Facilitated successful IS development & 1 & & & & \\
\hline Ensured the developed system met user requirements & 2 & 3 & 4 & * & \\
\hline Ensured well-defined user requirements & 3 & & & & 6 \\
\hline Facilitated effective project control & 4 & & 9 & 1 & \\
\hline Led to the delivery of a high-quality system & 5 & 4 & 7 & * & \\
\hline $\begin{array}{l}\text { Facilitated effective communication between developers } \\
\text { and users }\end{array}$ & 6 & & 2 & & 7 \\
\hline
\end{tabular}




\begin{tabular}{|c|c|c|c|c|c|}
\hline Role of standard method use & 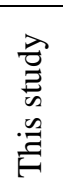 & 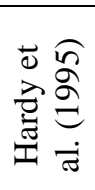 & 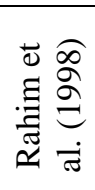 & 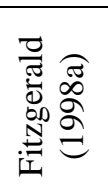 & 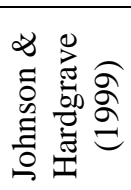 \\
\hline Facilitated user participation in development process & 7 & 5 & 3 & & \\
\hline Facilitated effective communication among developers & 8 & & 5 & $*$ & \\
\hline Ensured timely development of the system & 9 & 8 & & $*$ & 8 \\
\hline Enabled us to manage costs effectively & 10 & & & $*$ & \\
\hline Allowed movement of developers between projects & 11 & & & * & \\
\hline Led to a high level of productivity of the project team & 12 & 6 & 1 & & 3 \\
\hline
\end{tabular}

Figure 2: Relative agreement with negative statements about standard methods

$$
\begin{aligned}
& \text { Did not cover entire process }(\mu=2.84, \mathrm{n}=75) \\
& \text { Ignored people-related factors }(\mu=2.58, \mathrm{n}=74)
\end{aligned}
$$

Difficult or time-consuming to learn/use $(\mu=2.53, \mathrm{n}=73)$

Constrained developer creativity or flexibility $(\mu=2.48, n=73)$

Difficult to adapt to a specific situation $(\mu=2.51, \mathrm{n}=74)$

Ignored developers' knowledge and experience $(\mu=2.21, \mathrm{n}=73)$

Did not match how systems are developed $(\mu=2.44, n=75)$

Constrained effective user participation $(\mu=2.21, \mathrm{n}=75)$
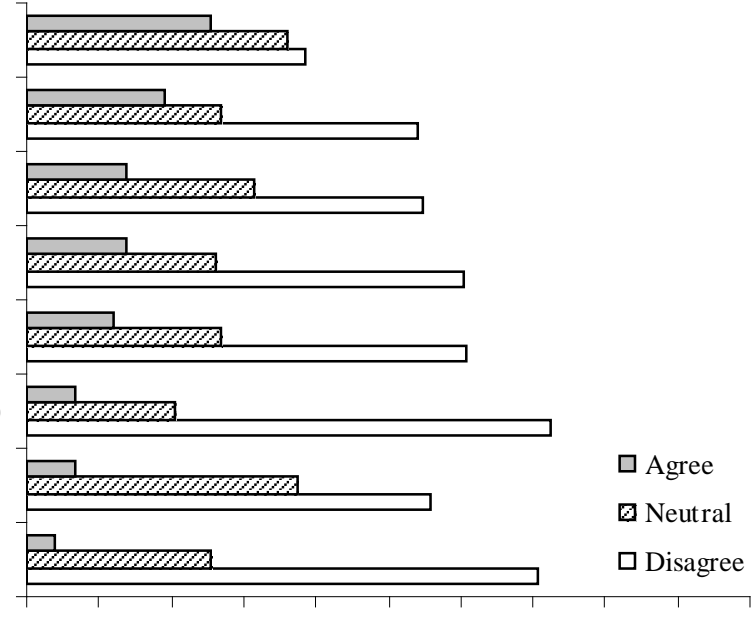

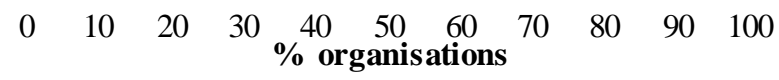

\begin{tabular}{|c|c|c|c|c|c|c|}
\hline Role of standard method use & 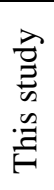 & 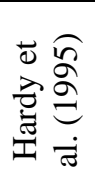 & 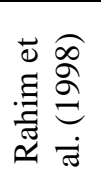 & 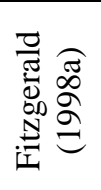 & 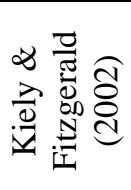 & 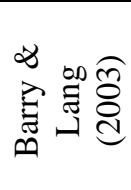 \\
\hline Total number of factors ranked & 8 & 7 & 4 & 10 & $3+$ & 6 \\
\hline Did not cover the entire development process & 1 & 2 & 3 & & & \\
\hline Ignored people-related factors in development & 2 & & & $*$ & & \\
\hline Was difficult or time-consuming to learn or use & 3 & 1,6 & $1,2,4$ & 1,2 & 2 & $1,3,4,6$ \\
\hline Constrained developer creativity and flexibility & 4 & & & $*$ & & \\
\hline Was difficult to adapt to a specific situation & 5 & & & $*$ & & \\
\hline Ignored developers' knowledge and experience & 6 & & & * & & \\
\hline Did not match how systems are actually developed & 7 & & & 3 & & 5 \\
\hline $\begin{array}{l}\text { Constrained effective user participation in the } \\
\text { development process }\end{array}$ & 8 & & & & & \\
\hline
\end{tabular}

Table 9: Comparative ranking of limitations of standard methods

\subsection{Proposed Changes in Standard Method Use}

All respondents to the survey were asked to comment on anticipated changes to the use of standard methods within their organisations. Of the 69 responses (Table 10), 29\% indicated that there would be little or no change to current practice in this area. Three of these respondents did not use a standard method - and have therefore indicated that they will continue to not use a method. Only one respondent envisaged less use of standard methods, commenting that the single reported instance of standard method use in his or her organisation was atypical.

The majority of respondents (70\%) indicated that standard method use would increase in some way in their organisations over the next three years. These responses were analysed and grouped into five categories, comprising more frequent use of standard methods, the continuous improvement or refinement of existing 
standard methods, and the expected introduction of standard methods in organisations (including three nonusers of a standard method), more formalised use of standard methods (sometimes explicitly in order to increase control of aspects of IS projects or outsourced development), and use of a greater variety of types of standard methods (possibly depending on the nature or size of the IS project).

Table 10: Changes in standard method use

\begin{tabular}{|l|c|}
\hline & $\begin{array}{c}\text { \% organisations } \\
(\mathrm{n}=69)\end{array}$ \\
\hline Little or no change & 29 \\
Less use of standard methods & 1 \\
More use of standard methods & 70 \\
More frequent use of methods & 15 \\
More formal use of methods & 15 \\
Refinement of existing methods & 17 \\
More types of methods used & 9 \\
Introduction of standard methods & 15 \\
\hline
\end{tabular}

These results are consistent with other empirical studies, which found that standard method use was unlikely to decrease and that relatively large proportions of organisations intended to increase their use of standard methods (Barry and Lang 2001; Fitzgerald 1998a; Schambach and Walstrom 2002-2003). Certainly, it would seem that the practice of standard method use is institutionalised in the majority of organisations that participated in this survey, and that many of them perceive some value in using standard methods. As one respondent noted, the use of a standard method was "embedded in the culture" of the organisation.

\section{CONCLUSIONS}

This study has provided an updated assessment of standard method use in IS development in New Zealand organisations based on empirical data from actual IS projects. Where available, data from other countries was compared to the New Zealand findings.

Standard methods were used by $92 \%$ of the respondent organisations and in 91\% of the reported projects. These levels are higher than those for other countries reported in the IS literature, and confirm the preliminary findings of Taylor (2000). Consistent with prior studies, the data presented here showed a positive correlation between standard method use and organisational size. Interestingly, the survey findings suggest that the use of project management methods may be increasing in importance in IS development - a possible reflection of the modern IS development landscape with growth in packaged software acquisition and outsourced development. At an organisational level this may also reflect the increasing level of offshore ownership of New Zealand business entities, with the consequent use of systems brought in from parent companies - perhaps with a level of customisation to the local environment. In both contexts there would be greater need for deployment management than for development management, and this may explain the increased visibility of standard project management methods. Further research into changes in the development and business landscape and the impact of such changes on management practices would help to clarify these outcomes.

Despite a comparatively high level of standard method use, the findings of this study support Taylor's (2000) suggestion that New Zealand organisations often use standard methods in IS development in an ad hoc and pragmatic way. For example, common reasons given for not using a standard method in particular IS projects included the characteristics of the project or an informal organisational approach to IS development. Further, the majority of organisations using standard methods developed their own in-house methods (81\%), 60\% of these drawing on aspects of commercial or published methods. Finally, only $18 \%$ of the organisations who provided information on their extent of standard method use always used their method as specified. This implies the partial use or adaptation of standard methods in some IS projects. This pragmatic use of methods could be interpreted as reflecting a growing maturity in organisations, in that they use methods very much as a means to an end, rather than seeing them as an end in themselves - the latter approach being characteristic of the 1970s and 1980s when methods and methodologies were used with almost blind adherence. It may also reflect the fact that the complexity of both contemporary software systems and the business contexts in which they operate are less conducive to management using structured (semi-) formal methods. This would be naturally consistent with the increasing use of similarly lightweight and flexible software engineering methods, commonly grouped under the agile descriptor. While we ourselves did not pursue the question of why organisations used (or did not use) particular methods this would be a topic of further research interest.

The levels of agreement given to various benefits of standard method use in IS development were generally high and are consistent with those reported in prior studies (Hardy et al. 1995; Rahim et al. 1998). The results of this survey support observations in the IS literature highlighting the importance of standard method use for facilitating IS development success, particularly in relation to effective project control and the delivery of a high quality system that meets users requirements. Respondents tended to disagree with the various limitations of standard method use presented to them, although 25\% did agree that the standard methods they use do not cover the entire development process.

Despite various criticisms of standard methods made in the IS literature, it appears that many New Zealand organisations anticipate extending their use of standard methods in IS development. The overall conclusion is that the use of standard methods - especially where this includes standard project management methods continues to play an important role in relatively large New Zealand organisations. However, there appears to be some variation in how and why standard method use is enacted in practice, suggesting that further research could usefully explore the various dimensions of standard method-in-use (Fitzgerald et al. 2002; Mathiassen and Purao 2002). 


\section{ACKNOWLEDGEMENTS}

The authors would like to thank all respondents to the survey reported in this paper. This research was funded through a Top Achiever Doctoral Scholarship by the Tertiary Education Commission of New Zealand.

\section{REFERENCES}

Amoako-Gyampah, K. and White, K.B. (1993) User involvement and user satisfaction. Information \& Management 25: 1-10.

Avison, D.E. and Fitzgerald, G. (1999) Information systems development. In Currie, W.L. and Galliers, R.D. (Eds), Rethinking Management Information Systems. Oxford University Press, Oxford, pp. 250278.

Avison, D.E. and Fitzgerald, G. (2003) Where now for development methodologies? Communications of the ACM 46(1): 79-82.

Avison, D.E., Shah, H.U., Powell, R.S. and Uppal, P.S. (1992) Applying methodologies for information systems development. Journal of Information Technology 7(3): 127-140.

Bansler, J.P. and Bødker, K. (1993) A reappraisal of structured analysis: Design in an organizational context. ACM Transactions on Information Systems 11(2): 165-193.

Barry, C. and Lang, M. (2001) A survey of multimedia and web development techniques and methodology usage. IEEE Multimedia 8(2): 52-60.

Barry, C. and Lang, M. (2003) A comparison of 'traditional' and multimedia information systems development practices. Information and Software Technology 45: 217-227.

Butler, T. and Fitzgerald, B. (1999) Unpacking the systems development process: An empirical application of the CSF concept in a research context. Journal of Strategic Information Systems 8(4): 351371.

Chatzoglou, P.D. (1997) Use of methodologies: An empirical analysis of their impact on the economics of the development process. European Journal of Information Systems 6(4): 256-270.

Chatzoglou, P.D. and Macaulay, L.A. (1996) Requirements capture and IS methodologies. Information Systems Journal 6(3): 209-225.

Coughlan, J., Lycett, M. and Macredi, R.D. (2003) Communication issues in requirements elicitation: A content analysis of stakeholder experiences. Information and Software Technology 45(2): 525-537.

Dillman, D.A. (2000) Mail and Internet Surveys: The Tailored Design Method, 2nd edn. John Wiley and Sons, New York.

Eva, M. and Guilford, S. (1996) Committed to a radical approach? A survey of systems development methods in practice. In Jayaratna, N. and Fitzgerald, B. (Eds), Lessons Learned From the Use of Methodologies: Proceedings of the Fourth Conference of the British Computer Society Information Systems Methodologies
Specialist Group, University College of Cork, Cork, pp. 87-96.

Ewusi-Mensah, K. (1997) Critical issues in abandoned information systems development projects. Communications of the ACM 40(9): 74-80.

Fitzgerald, B. (1996) Formalized systems development methodologies: A critical perspective. Information Systems Journal 6(1): 3-23.

Fitzgerald, B. (1997) The use of systems development methodologies in practice: A field study. Information Systems Journal 7(3): 201-212.

Fitzgerald, B. (1998a) An empirical investigation into the adoption of systems development methodologies. Information \& Management 34: 317-328.

Fitzgerald, B. (1998b) An empirically-grounded framework for the information systems development process. In Hirschheim, R., Newman, M. and DeGross, J.I. (Eds), Proceedings of the International Conference on Information Systems (Helsinki, Finland), Association of Information Systems, Altanta, GA, pp. 103-114.

Fitzgerald, B. (1998c) A tale of two roles: The use of systems development methodologies in practice. In Jayaratna, N., Wood-Harper, A.T. and Fitzgerald, B. (Eds), Educating Methodology Practitioners and Researchers, Springer-Verlag, London, pp. 89-96.

Fitzgerald, B. (2000) System development methodologies: The problem of tenses. Information Technology and People 13(3): 174-185.

Fitzgerald, B., Russo, N.L. and Stolterman, E. (2002) Information Systems Development: Methods in Action. McGraw-Hill, London.

Fitzgerald, G., Philippidis, A. and Probert, P. (1999) Information systems development, maintenance, and enhancement: Findings from a UK study. International Journal of Information Management 19(4): 319-329.

Gowan, J.A. and Mathieu, R.G. (2005) The importance of management practices in IS project performance. Journal of Enterprise Information Management 18(2): 235-255.

Groves, L., Nickson, R., Reeve, G., Reeves, S., Utting, M. (2000) A survey of software requirements specification practices in the New Zealand software industry. In Proceedings of the Australian Software Engineering Conference (28-29 April), pp. 189-201.

Guinan, P.J., Cooprider, J.G. and Faraj, S. (1998) Enabling software team performance during requirements definition: A behavioral versus technical approach. Information Systems Research 9(2): 101125.

Hardy, C.J., Thompson, J.B. and Edwards, H.M. (1995) The use, limitations and customization of structured systems development methods in the United Kingdom. Information and Software Technology 37(9): 467-477.

Hidding, G.J. (1997) Reinventing methodology: Who reads it and why? Communications of the ACM 40(11): 102-109. 
Hornby, P., Clegg, C.W., Robson, J.I., Maclaren, C.R.R., Richardson, S.C.S. and O'Brien, P. (1992) Human and organizational issues in information systems development. Behaviour and Information Technology 11(3): 160-174

Huisman, M. and Iivari, J. (2002) The organisational deployment of systems development methodologies. In Kirikova, M., Grundspenkis, J., Wojtkowski, W., Wojtkowski, W.G., Wrycza, S. and Zupancic, J. (Eds), Information Systems Development: Advances in Methodologies, Components and Management, Kluwer Academic, New York, pp. 87-100.

Iivari, J., Hirschheim, R. and Klein, H.K. (2000/2001) A dynamic framework for classifying information systems development methodologies and approaches. Journal of Management Information Systems 17(3): 179-218.

Iivari, J. and Maansaari, J. (1998) The usage of systems development methods: Are we stuck to old practices? Information and Software Technology 40(9): 501-510.

Jiang, J.J. and Klein, G. (1999) Risks to different aspects of system success. Information \& Management 36: 263-272.

Jiang, J.J. and Klein, G. (2000) Software development risks to project effectiveness. Journal of Systems and Software 52(1): 3-10.

Johnson, J., Boucher, K.D., Connors, K. and Robinson, J. (2001) The criteria for success. Software Magazine 21(1): S3-S11.

Johnson, R.A. and Hardgrave, B.C. (1999) Objectoriented methods: Current practices and attitudes. Journal of Systems and Software 48: 5-12.

Kautz, K., Hansen, B. and Jacobsen, D. (2004) The utilization of information systems development methodologies in practice. Journal of Information Technology Cases and Applications 6(4): 1-20.

Kautz K, McMaster T (1994) Introducing structured methods: An undelivered promise? - A case study. Scandinavian Journal of Information Systems 6(2):5978

Keil, M., Tiwana, A. and Bush, A. (2002) Reconciling user and project manager perceptions on IT project risk: A Delphi study. Information Systems Journal 12(2): 103-119.

Kiely, G. and Fitzgerald, B. (2002) An investigation of the information systems development environment: The nature of development life cycles and the use of methods. In Proceedings of the Eighth Americas Conference on Information Systems (Dallas), AIS, pp. 1289-1296.

Kiely, G. and Fitzgerald, B. (2003) An investigation of the use of methods within information systems development projects. In Korpela, M., Montealegre, R. and Poulymenakou, A. (Eds), Proceedings of the IFIP WG8.2 \& WG9.4 Working Conference on Information Systems Perspectives and Challenges in the Context of Globalization (Athens), IFIP, pp. 187198.

Kim, C.S. and Peterson, D.K. (2003) A comparison of the perceived importance of information systems development strategies by developers from the United States and Korea. Information Resources Management Journal 16(1): 1-18.

Linberg, K.R. (1999) Software developer perceptions about software project failure. Journal of Systems and Software 49: 177-192.

Ljung, K. and Allwood, C.M. (1999) Computer consultants' views of user participation in the system development process. Computers in Human Behaviour 15(6): 713-734.

Lyytinen, K. and Hirschheim, R. (1987) Information systems failures: A survey and classification of the empirical literature. Oxford Surveys in Information Technology 4: 257-309.

Madsen, S. and Kautz, K. (2002) Applying system development methods in practice: The RUP example. In Kirikova, M., Grundspenkis, J., Wojtkowski, W., Wojtkowski, W.G., Wrycza, S. and Zupancic, J. (Eds), Information Systems Development: Advances in Methodologies, Components and Management, Kluwer Academic, New York, pp. 267-278.

Martin, A. and Chan, M. (1996) Information systems project redefinition in New Zealand: Will we ever learn? Australian Computer Journal 28(1): 27-40.

Mathiassen, L. and Purao, S. (2002) Educating reflective systems developers. Information Systems Journal 12(2): 81-102.

McLeod, L., MacDonell, S. and Doolin, B. (2006) IS development practice in New Zealand organisations (unpublished manuscript, under review).

Nandhakumar, J. and Avison, D.E. (1999) The fiction of methodical development: A field study of information systems development. Information Technology and People 12(2): 176-191.

Pan, G.S.C., Pan, S.L. and Flynn, D.J. (2004) Deescalation of commitment to information systems projects: A process perspective. Journal of Strategic Information Systems 13: 247-270

Rahim, M.M., Seyal, A.H. and Rahman, M.N.A. (1998) Use of software systems development methods: An empirical study in Brunei Darussalam. Information and Software Technology 39: 949-963.

Roberts, T.L., Gibson, M.L. and Fields, K.T. (1999) Systems development methodology implementation: Perceived aspects of importance. Information Resources Management Journal 12(3): 27-38.

Roberts, T.L., Leigh, W. and Purvis, R.L. (2000) Perceptions on stakeholder involvement in the implementation of system development methodologies. Journal of Computer Information Systems 40(3): 78-83.

Robey, D., Welke, R.J. and Turk, D. (2001) Traditional, iterative, and component-based development: A social analysis of software development paradigms. Information Technology and Management 2(1): 53-70.

Russo, N.L., Hightower, R. and Pearson, J.M. (1996) The failure of methodologies to meet the needs of current development environments. In Jayaratna, N. and Fitzgerald, B. (Eds), Lessons Learned From the Use of Methodologies: Proceedings of the Fourth Conference 
of the British Computer Society Information Systems Methodologies Specialist Group, University College of Cork, Cork, pp. 387-394.

Sauer, C., Lau, C. (1997) Trying to adopt systems development methodologies: A case-based exploration of business users' interests. Information Systems Journal 7(4): 255-275.

Sawyer, S. (2001) A market-based perspective on information systems development. Communications of the ACM 44(11): 97-102.

Schambach, T.P. and Walstrom, K.A. (2002-2003) Systems development practices: Circa 2001. Journal of Computer Information Systems 43(2): 87-92.

Schmidt, R., Lyytinen, K., Keil, M. and Cule, P. (2001) Identifying software project risks: An international Delphi study. Journal of Management Information Systems 17(4): 5-36.

Standish Group International (1999) Chaos: A Recipe for Success (1998). The Standish Group International, West Yarmouth, MA.

Taylor, H. (2000) Information systems development practice in New Zealand. In Proceedings of the 13th Conference of the National Advisory Committee on Computing Qualifications (July, Wellington), pp. 367372.

Taylor, M.J., McWilliam, J., Forsyth, H. and Wade, S. (2002) Methodologies and website development: A survey of practice. Information and Software Technology 22: 381-391.

Truex, D., Baskerville, R. and Klein, H.K. (1999) Growing systems in emergent organizations. Communications of the ACM 42(8): 117-123.

Urban, J.L.P. and Whiddett, R.J. (1996) The relationship between systems development methodologies and organisational demographics: A survey of New Zealand organisations. In Information Systems Conference of New Zealand Proceedings (30-31 October, Palmerston North), pp. 179.

Vidgen, R., Madsen, S. and Kautz, K. (2004) Mapping the information systems development process. In Fitzgerald, B. and Wynn, E.H. (Eds), IT Innovation for Adaptability and Competitiveness, Kluwer Academic Press, Boston, pp. 157-172.

Warne, L. and Hart, D. (1996) The impact of organizational politics on information systems project failure - a case study. In Proceedings of the TwentyNinth Hawaii International Conference on System Sciences Vol. 4, IEEE, pp. 191-201.

Wastell, D. (1996) The fetish of technique: Methodology as a social defence. Information Systems Journal $6(1): 25-40$

Wastell, D. and Sewards, A. (1995) An information system profile of the UK manufacturing sector. Journal of Information Technology 10: 179-189.

Westrup, C. (1993) Information systems methodologies in use. Journal of Information Technology 8(4): 267-275.

Wixom, B. and Watson, H.J. (2001) An empirical investigation of the factors affecting data warehousing success. MIS Quarterly 25(1): 17-41.
Wynekoop, J.L. and Russo, N.L. (1995) Systems development methodologies: Unanswered questions. Journal of Information Technology 10: 65-73.

Wynekoop, J.L. and Russo, N.L. (1997) Studying system development methodologies: An examination of research methods. Information Systems Journal 7(1): 47-65. 